\title{
Gender-Based Research Capacity Building as Transitional Process within the South African Higher Education Context: Towards A Community of Practice
}

\author{
Christel Marais ${ }^{1}$ \\ Karien du Bryun² \\ Dr Charlene Downing 3 \\ Fathima Mahomed ${ }^{4}$ \\ Idah Naile 5 \\ Onica Matsheke 6 \\ Prof Emsie Dicks ${ }^{7}$ \\ Osayuwamen Omoruyi ${ }^{8}$ \\ Reshma Maharajh ${ }^{9}$ \\ Prof Jeanette Kearney ${ }^{10}$ \\ Christa Grobler ${ }^{11}$

\begin{abstract}
${ }^{1}$ Faculty of Management Science, Vaal University of Technology, South Africa, Email: christel@vut.ac.za 2VUT Goldfields Library, Vaal University of Technology, South Africa, Email: karienbd@vut.ac.za ${ }^{3}$ Research and Higher Degrees, Vaal University of Technology, South Africa, Email: Carlene.downing@gmail.com

4Faculty of Management Sciences, Vaal University of Technology, South Africa, Email: fathima@vut.ac.za ${ }^{5}$ Faculty of Management Sciences, Vaal University of Technology, South Africa, Email: idahn@vut.ac.za 6Faculty of Management Sciences, Vaal University of Technology, South Africa, Email: onica@vut.ac.za 7Faculty of Human Sciences, Vaal University of Technology, South Africa, Email: emsie@vut.ac.za ${ }^{8}$ Faculty of Management Sciences, Vaal University of Technology, South Africa, Email: osayuidameno@vut.ac.za ${ }^{9}$ Faculty of Human Sciences, Vaal University of Technology, South Africa, Email: resshma@vut.ac.za

${ }^{10}$ Faculty of Human Sciences, Vaal University of Technology, South Africa, Email: jkearney@vut.ac.za ${ }^{11}$ Faculty of Applied and Computer Sciences, Vaal University of Technology, South Africa, Email: christa@vut.ac.za
\end{abstract}

Doi:10.5901/mjss.2014.v5n23p97

\section{Abstract}

The shifting political landscape of higher education in South Africa has challenged academia at universities of technology to embrace a "new way of doing" which includes the broader research agenda. Met with an initial sense of resistance and noticeable fear of the unknown by the staff of these institutions, it became apparent that communities of practice (CoP) need to be established, especially among female academia. As a result the Women in Research (WiR) initiative was formed in order to establish a research culture through capacity-building initiatives. The purpose of this paper is to uncover the meaning-making of the WiR initiative for participants as they develop their research identity through a collective scholarly engagement. A qualitative, phenomenological and contextual paradigm with non-probability, purposive self-selection sampling was employed. This collective approach helped the participants to form a research identity, provided a nurturing environment characterised by trusting engagement, mentorship and connectedness. Lastly, intellectual companionship and a sense of coherence took centre stage. The potential spin offs of such a WiR initiative need to be recognised and embraced as the research community strives towards capacity building and research outputs within the broader higher educational context.

Keywords: research culture; community of practice; gender-based research capacity building; females in academia; collaboration; phenomenology

\section{Introduction and Background}

The continuous trajectory of transition in higher education remains a global phenomenon (Bai, Milwater, \& Hudson, 2013; Jensen, 2006). The focus is increasingly being placed on scholarly outputs as a measurable outcome of this transition. 
The need to cultivate a research culture, in what was previously a technikon environment, proved to be a reality many South African universities faced within the context of a the free and democratic post-apartheid scholarly environment. This transition has been a long and arduous process which challenged academia both on a personal and professional level (Garnett \& Mahomed, 2012; Managa, 2013; Petersen \& Gravett, 2000; Tessens, White, \& Web, 2011; Wolfinger, 2008). Although progress has been made, the advancement of Black and female researchers remains a recurring discussion point on the current transformation agenda (Council of Higher Education, 2009, 2013; Managa, 2012).

\subsection{Transition into a research culture}

The shift in the political landscape has meant that academia at universities of technology (UoT) have had to embrace a "new way of doing" (Johnson \& Louw, 2014; Katz \& Martin, 1997) where the focus has shifted from teaching to research. UoTs traditionally came from a teaching environment that was primarily focused on the practical application of theory as opposed to the abstraction thereof through scientific research efforts and academic scholarship. In this new paradigm academics have now had to commit themselves to an active engagement within the broader research agenda. This was met with an initial sense of resistance and noticeable fear of the unknown by the staff of these institutions.

The current research agenda advocates interdisciplinary collaborative research efforts where a platform is created to share "skills, techniques or concepts originating from different disciplines" (Van Rijnsoever \& Hessels, 2011). This creates a conducive knowledge-focused environment for social processes and is an inherent aspect of collaboration which ultimately enhances the overall prosperity of a research career (Bozeman, Fay, \& Slade, 2013). This situation provides an opportunity for female academics to increase their low publication rates (Council of Higher Education, 2013; Selematsela, 2011; Tessens et al., 2011).

\subsection{Women-in-Research (WiR)}

The Research Directorate of the Vaal University of Technology (VUT) made a strategic decision (Wenger, McDermott, \& Snyder, 2002:17) to launch a WiR programme to establish a community of practice (CoP). The focus of this initiative was to encourage and motivate female staff members to embrace a culture of research engagement through mutual accountability (Garnett \& Mahomed, 2012:82-89; Hubert, Newhouse, \& Vestal, 2001; Wenger, 2006). CoP is a term coined by Lave and Wenger (1991), and is "characterised by a common domain, a shared domain of interest". The CoP at VUT is in its fourth year of an established practice and provides a common ground for uplifting of the profile of women at the Institution. Membership therefore implies a commitment to the initiative as such and the shared collective engagement as a group and as an individual (Selepe, Grobler, Dicks, \& Oldewage-Theron, 2012). The common space is shared by novice and experienced researchers alike; and the interest in research is desired by all. Critical engagement and discourse are central to enhanced learning, and lead to inter-collegial and collaborative engagement among members.

WiR operates on an open, participative and trusting environment which is shared by all members. This creates a sense of unity and belonging (Selepe et al., 2012), thereby transforming the "individualistic culture" of traditional academic engagement (Theron, 2002) into a union of collective engagement. This social interaction acts as an intrinsic motivator, enhancing collaboration (Bai et al., 2013; Van Rijnsoever \& Hessels, 2011) and connectedness within the team (Selepe et al., 2012). This results in a dynamic synergy between critical social engagement and intellectual companionship (Katz \& Martin, 1997) while developing a research identity. This sense of coherence amplifies the comprehensibility, manageability and meaningfulness of the research engagement (Bezuidenhout \& Cilliers, 2010).

\subsection{Nurturing nature of engagement}

This environment is conducive to the sharing and transferring of knowledge and exposure to a wide array of epistemological and ontological research repertoires culminating in a cross-fertilisation of ideas and new insights (Katz \& Martin, 1997). The role of mentoring and peer engagement also plays a vital role in this developmental initiative (Begley, 2013; Tessens et al., 2011). The developmental roles of mentorship_both male and female-add to the professional development of members (Petersen \& Gravett, 2000). Moreover, mentorship is also seen as an enabler within the research journey (Managa, 2013).

Operating within a traditionally "male-dominated" work environment (Elg \& Jonnergård, 2010; Managa, 2013; Petersen \& Gravett, 2000; Rabe \& Rugunanan, 2012), female academics often have to fight to be acknowledged in terms of their researcher identity. Jokingly referred to as yet another meeting of the "Tupper-club" by their male counterparts in 
passing, the authors' reflections on their meaning-making process within a transformed South African higher educational environment revolved around the value of their gender-based multidisciplinary collaborative engagement as they construct their researcher identity.

\section{Research Design}

A qualitative, phenomenological and contextual paradigm was used for the study. The paradigm was suitable for a the naturalistic enquiry in which the issue of human complexity and uniqueness of each individual could be explored (Grove, Burns \& Gray, 2013) and where trust is part of the complexities of the realities shared.

According to Sieber and Tolich (2013), the best research ideas usually arise from ones' own lived realities as a participant of the living world. The authors of this study wished to uncover the meaning-making of the WiR initiative and capture the positive expressions of the contributions (Houster, 2012:154-155) to the capacity-building initiative and transference of the research culture at a UoT. Within this contextual approach, where trust is part of the complex realities as experienced by the participants, the natural setting is both dynamic and challenging (Olesen, 2013). In this study the researchers wished to understand how the members of the WiR initiative find meaning (Houster, 2012:154-155). The participants acted as key informants (Grove et al., 2013:84) and shared lived experiences during monthly interactions in 2012. We followed the ethical guidelines in The Helsinki Declaration and the study was approved by the Research and Innovation Meeting of the UoT in 2012. The ethical clearance number is 01112012.

\subsection{Sampling and participants}

Non-probability, purposive self-selection sampling was used (Fox \& Bayat, 2013). Schutt (2012:157) describes purposive sampling as the identification of a subset of the population which can act as key informants based on their knowledge of and willingness to share their experiences and thoughts about a specific phenomenon (Bernard, 2013; Quinlan, 2011). The research purpose, objectives, design and target populations informed this sampling choice (Bernard, 2013; Edmonds \& Kennedy, 2013).

The group consisted of 12-18 members at any given time. The members included academic and non-academic staff, ranging from novices to and subject specialists. The membership included women who joined at the beginning of the initiative as well as women who joined later on. Most of the members are currently working towards a Masters or PhD qualification, while others have an established publication record.

\subsection{Data collection}

Interpretative phenomenological research design aims to explore the meaning-making process of participants within their personal and social contexts. This implies an acknowledgement that meaning making involves the participants' collective cognitive, linguistic, affective and physical being as expressed in their shared experiences (Smith \& Eatough, 2008). Two data collection methods were used during the data collection phase. One was a personal reflection by way of a diary and the other a metaphor related to music or art. Eliciting a process of meaning making by reflecting upon experiences of participants in a specific context was deemed appropriate with regard to the interpretive nature of this research (Morehouse, 2012). Diaries are regarded as qualitative research tools which aid in the solicitation of personalised life records which can be kept on request (Jones, 2000; Layder, 2013). Solicited diaries refer to key informants' accounts of their lived realities at the request of the researcher (Mackrill, 2008) and thus imply a process of co-construction.

Using a structured format (Mackrill, 2008), the diary method was based on two intervals of data collection from May to July 2012. The following two questions were sent via email to all participants:

- What does it mean to you to be part of the WiR initiative?

- If WiR should be music or art, what would the tune/s and lyric/s or picture/s be for you?

Participant responses to the given metaphors facilitated their reflection upon their understanding of complex concepts (Henderson, Holland, McGrellis, Sharpe, \& Thomson, 2012; Jensen, 2006) which in turn provided insight into their own reality (Dodd, 2002). This allowed for a richer non-linear exploration and appreciation of lived realities that illustrates values, assumptions and practices (Dexter \& LaMagdaleine, 2002). The participants actively constructed their story of themselves and included their emotions and making sense of happenings and events. These reflections may have been written with the researcher in mind, with the knowledge that the reflections would be read and interpreted by another person (Jacelon \& Imperio, 2005:991-997). Throughout the data collection, however, a high level of commitment to provide the detail was evident (Furness \& Garrud, 2010:262-272). All the diary entries were collected electronically 
using personal computers and e-mailed responses (Mackrill, 2008).

The selected data collection method encouraged participants to reflect in everyday language through recalling personal memories which enabled in-depth description of the phenomena (Dexter \& LaMagdaleine, 2002; Sá, 2002). The richness of description and the embellishment with pictures, songs and depth of detail facilitated the conceptualisation of the participants' journey while they were part of the group (Furness \& Garrud, 2010:262-272).

Themes arising from the first round of data collection were purposefully shared with participants to add to the transparency and authenticity of the process. This provided an opportunity for the debriefing of participants and facilitated continued commitment to the research objectives. In addition, this debriefing afforded participants an additional opportunity to critically reflect upon the independent coder's interpretation of data (Storey, 2008).

\subsection{Data analysis}

Analysis involves the search for patterns within collected data (Bernard, 2013). The diaries of the participants were stored in a Word programme. The researchers made use of the services of an independent coder who conducted an independent analysis of the data while the researcher analysed the data. The independent coder was selected on the grounds of her expertise within the qualitative research world and humanities. The data analysis occurred independently and both parties met after completion of the data analysis for consensus conversations.

Saldaña (2013:60) emphasises the need for alignment between the nature and goals of a study and the chosen coding method. Tesch's method (Creswell, 2014; Tesch, 1990) which follows seven progressive steps of increasing complexity and thoroughness of analysis guided the analysis. The transcriptions were read with attention in order to create a picture of the "whole" experience as told by the participants. A general sense of the information was obtained. The researcher wrote down any ideas that came to mind during this reading phase. Taking one diary entry at a time, in no preferential order, the researcher conducted a careful analysis to determine the underlying information as provided by the participants. We read through the diary entries repeatedly and "lived" with the transcripts for a substantial time period to ensure that all relevant statements were identified. The researchers took the list of statements back to the main data, and topics were abbreviated to codes. The codes were placed next to the appropriate segments of the text. The most descriptive word/s or wordings for the topics were used as main themes and sub-themes. The coders then grouped related and interrelated topics together to reduce the total list of categories. The coders remained open to new emerging themes and reworked the information as required. A final decision list for each theme was made and all the data was then categorised into the various themes. A preliminary analysis on the assembled data in each category was then performed. The coders worked in constant interaction and open discussion identifying similarities and differences. Due to the intense method of working there was no need to re-code the data. Once the analyses had been done, the researcher and independent coder met to conduct a consensual exercise regarding the reduction of the data into categories, subcategories and main emergent themes (Smith \& Firth, 2011:52-62). The use of the independent coder ensured triangulation of the data. In addition, we adhered to the principles of trustworthiness by prolonged engagement in the field, data collection at different occurrences, member checking by providing themes to the members for corroboration and dense description of the experiences (Krefting, 1991:214-222).

\section{Findings and Discussion}

The interaction of this group was enhanced by a complex variety of existing and newly formed friendships. Like a friendship, members of the WiR group became helpmates, comforters, confidants and soul mates. The reciprocal nature of this interaction focused on the empowerment of members. The participants expressed a shared, deep sense of involvement and a sense of belonging to a group that enabled them to feel and be empowered in the multi-realities of life and of being women. Initially members became part of the group because the various heads of departments nominated them, but current membership is based on self-selection. The core of participants was part of the original group started in 2010. A sense of belonging is described by Pitonyak (2010:2) as not only contributing to one's self-worth, but to a feeling of kinship for many people. Indeed, it appears to be a basic human need-as basic as food and shelter.

A sense of belonging was shared related to expected outputs of research in the following statements: "... implies an obligation ..." and "... active participation, commitment and targetable outputs". The Research Directorate at the University of Technology aligned the development of the WiR initiative with the National Research Foundation's philosophy to empower and increase the number of women researchers (Selematsela, 2011). The initiative-transitional in nature-is critical in terms of developing and strengthening the participants' ability in the working world of research regardless of whether they are novices or recognised researchers. Human beings are always concerned with establishing 
and maintaining relatedness to others, social institutions, environments and self (Berlin \& Johnson, 1989; Hagerty, LynchSuer, Patusky, Bauwsema, \& Collien, 1992; Wayne, 1984) while constructing a sense of belonging which can be clearly seen in this group of women.

The gender relatedness of women resulted in comments from non-participating members such as "why are there no men in research?" and even being labelled as the "tupper club" by their male counterparts, implying the Tupperware parties held for women where plastic household products are sold. A participant responded by describing the "exclusiveness" of the research initiative in the following statement related to the current research landscape at UoT: "...many research forums on campus, which are mostly male dominant, is it good to meet with women only, and to share experiences".

The participants alluded to the fact that part of the benefit of attending was the learning experience. The capacity building and research collaboration within the world of research and the avenue of expression for the individual and being a member of a group (Aziz, Shams, \& Khan, 2011:303-323) are of critical value. The participants described the significance of their attendance and the learning experience in the following ways: "we have a lot in common"; "...be part of this group as I feel that"; "we understand each other better"; "valuable, too often meet other women doing research on campus"; and "It always involves smiles and jokes, and I always leave feeling positive and enlightened".

According to Walton and Cohen (2007:83), are of the view that in academic and professional settings, members of socially stigmatised groups including women are more uncertain of the quality of their social bonds and thus are more sensitive to issues of social belonging. Women in higher institutions of learning are not an exception as the mutually dependent relationships formed during academic and social interaction serve to reinforce women's experiences of institutional membership, or cause conflict if one aspect of integration is more demanding than the other.

The initiative also served as a platform of getting to know the women working at the UoT-academic and nonacademic. Participants reported their shared exploration and sharing as follows: "feeling of togetherness" to connect to the people within the group; "much progress and energy to write" as expression of enthusiasm. Members experienced the get-togethers as stimulating and energising which helped them to "carry on" with all the expectations, roles and responsibilities of being a woman. This built "a secure and safe environment", and contributed positively to a network of learning. Another participant spoke of what the meetings meant to her as the group became larger: "New members are also often joining, and I am more aware of who is working where, and doing what around campus".

The participation and learning was compared to the journey of life which includes having ups and downs. The talking and becoming more confident as a researcher was expressed in the following statements: "Life is a continuous climb. The more you climb the more you grow"; "I realize that it gets hard sometimes \& I know that life can sometimes be a bumpy ride @ times but if you choose to ...", and "No matter how light or heavy it feels, it always makes a big difference".

The participant discussed how their "initial relationship" with research was one of intense fear and uncertainty. Engaging within a protected and safe environment allowed them to change their perceptions and views on research. "Over the last 10 years my research journey has slowly but surely taken form"; and "Being part of a group where learning and talking research is shared has lead positively to ignite a positive researcher identity and research confidence for the participants".

Another participant shared the feeling of what it meant to move forward and have goals for the group and as an individual: "The bumble bee is working at a feverish pace, because time is of the essence. Same as our groups". The interconnection between the personal and professional life are described as "... guess these textural differences reflect the way I feel about my own personal life as well". The deeper meaning and growth as a researcher, for example, was expressed as, "Like in research - sometimes you have wonderful moments (good season) and get wonderful research articles and then for days you can't get anything nice (bad season)".

Research companionship occurred during mutual interactions, and the depth of the interactions moved the participants from a distant engagement to a place of total immersion "the more I became engaged with research the more I enjoyed it and the more it became a "dream/goal"; "I must just practise, like a musician, they do it for hours a day - it is something that I have to learn, like a new piece of music, just keep on going! The exposure to the WiR has opened up 'new worlds' for me in terms of what research actually is".

Motivation is central to the sense of belonging and meaning-making of being a member of the group. The participants experienced the group as a platform where a variety of avenues were available to them, ranging from selfexploration to contributing to the overall strategic goals of the higher education institution. The participants described the inter-relationship between the individual and the institution, as "research in VUT will empower me as a woman to contribute towards VUT research output".

The learning and need for sharing expertise and knowledge creates a learning environment. A participant 
expressed her usefulness within the group and being an inspiration as "being part of this group has shown me that some ladies at VUT look up to me and require my expertise".

Participants were also in the process of completing their Masters or PhD studies. The initiative thus also contributed towards their growth in their studies; for example, one participant said "my plan currently, to make significant progress with my thesis first. I am, however, excited that I can be part of a collective effort regarding producing an article, and hope that it will be published soon".

\section{Concluding Remarks and Implications for Practice}

The overall meaning making process of WiR is deemed a positive empowerment initiative within the broader research agenda of South Africa. Researchers, and in particular female researchers, could gain from a collective approach to the formation of their research identity. By providing a nurturing environment, characterised by a trusting engagement, mentorship and connectedness, VUT is creating an opportunity for intellectual companionship and coherence. The potential spin-offs of WiR initiatives should be acknowledged and embraced as the research community strives towards capacity building and research outputs within the broader higher educational context.

\section{References}

Aziz, A., Shams, M., \& Khan, K. (2011). Participatory action research as the approach for women's empowerment. Action Research, 9(3), 303-321.

Bai, L., Milwater, J., \& Hudson, P. (2013). Factors that influence Chinese TEFL academics' research capacity building: An institutional case study. Asia-Pacific Education Researcher, 22(2), 119-126.

Begley, C. (2013). Successful research capacity building in academic nursing and midwifery in Ireland: An examplar. Nurse Education Today, 1-7.

Berlin, S., \& Johnson, C. G. (1989). Women and autonomy, using structural analysis of social behaviour to find autonomy with connections. Psychiatry, 52(1), 79-95.

Bernard, H. R. (2013). Social research methods: Qualitative and quantitative approaches. (2nd ed.). Thousand Oaks: Sage.

Bezuidenhout, A., \& Cilliers, F. V. N. (2010). Burnout, work engagement and sense of coherence in female academics in highereducation institutions in South Africa. South African Journal of Industrial Psychology, 36(1), 1-10.

Bozeman, B., Fay, D., \& Slade, C. P. (2013). Research collaboration in universities and academic entrepreneurship: The state-of-the-art. The Journal of Technology Transfer, 38(1), 1-67.

Grove, S. K., Burns, N., \& Gray, J. R. (2013). The practice of nursing research: Appraisal, synthesis and generation of evidence. Missouri: Elsevier.

Council of Higher Education. (2009). Institutional cultures and higher education leadership: Where are the Women? [Online] Available: http://www.che.ac.za/media_and_publications/research/institutional-cultures-and-higher-education-leadership-where-are (February 13, 2014)

Council of Higher Education. (2013). Annual report of the Council on Higher Education 2012/2013. [Online] Available: http://www.che.ac.za/sites/default/files/publications/CHE\%20Annual\%20Report\%202012_2013.pdf (February 13, 2014)

Creswell, J. (2014). Research design: Qualitative, quantitative and mixed methods approaches. (4th ed.). Thousand Oaks: Sage.

Dexter, S., \& LaMagdaleine, D. R. (2002). Dominance theatre, slam-a-thon, and cargo cults: Three illustrations of how using conceptual metaphors in qualitative research works. Qualitative Inquiry, 8(3), 362-380.

Dodd, S. D. (2002). Metaphors and meaning: A grounded cultural model of US entrepreneurship. Journal of Business Venturing, 17, 519-535.

Edmonds, W. A., \& Kennedy, T. D. (2013). An applied reference guide to research design: Quantitative, qualitative and mixed methods. Thousand Oaks: Sage.

Elg, U., \& Jonnergård, K. (2010). Included or excluded? The dual influences of the organisational field and organisational practices on new female academics. Gender \& Education, 22(2), 209-225.

Fox, W., \& Bayat, M. S. (2013). A guide to managing research. Cape Town: Juta.

Furness, P. J., \& Garrud, P. (2010). Adaptation after facial surgery: Using the diary as a research tool. Qualitative Health Research, 20(2), 262-272.

Garnett, A., \& Mahomed, F. E. (2012). I want to publish but ...: Barriers to publishing for women at a University of Technology. Perspectives in Education, 30(2), 81-90.

Hagerty, B. M., Lynch-Suer, J., Patusky, K. L., Bauwsema, M., \& Collien, P. (1992). Sense of belonging: A vital mental health concept. Archives of Psychiatrist Nursing, 6(3), 172-177.

Henderson, S., Holland, J., McGrellis, S., Sharpe, S., \& Thomson, R. (2012). Storying qualitative longitudinal research: Sequence, voice and motif. Qualitative Research, 12(1), 16-34.

Houster, J. (2012). Nursing research reading, using and creating evidence. (2nd ed.). Sudbury: Jones and Bartlett Learning.

Hubert, C., Newhouse, B., \& Vestal, W. (2001). Building and sustaining communities of practice. Houston: American Productivity Centre. 
Jacelon, C. S. \& Imperio, K. I. (2005). Participant diaries as a source of data in research with older adults. Qualitative Health Research, 15(7), 991-997.

Jense, D. (2006). Metaphors as a bridge to understanding educational and social contexts. International Journal of Qualitative Methods, $5(1), 36-54$.

Johnson, B. J., \& Louw, A. (2014). Building a research culture from scratch at a University of Technology. Mediterranean Journal of Social Sciences, 5(1), 151-164.

Jones, R. K. (2000). The unsolicited diary as a qualitative research tool for advanced research capacity in the field of health and illness. Qualitative Health Research, 10(4), 555-567.

Katz, J. S., \& Martin, B. R. (1997). What is research collaboration? Research Policy, 26, 1-18.

Krefting, L. (1991). Rigor in qualitative research: The assessment of trustworthiness. American Journal of Occupational Therapy, 45(3), 214-222.

Lave, J., \& Wenger, E. (1991). Situated learning: Legitimate peripheral participation. Cambridge: Cambridge University Press.

Layder, D. (2013). Doing excellent small-scale research. Thousand Oaks: Sage.

Mackrill, T. (2008). Solicited diary studies of psychotherapy in qualitative research: Pros and cons. European Journal of Psychotherapy and Councelling, 10(1), 5-18.

Managa, A. (2012). A stepping stone for marginalised black women scholars: An assessment of the African Institute of South Africa (AISA) young graduates and scholars conference. AISA POLICYbrief, 67, 1-10.

Managa, A. R. (2013). Juggling work and life: Experiences of women in academic and research institutions in South Africa. New Voices in Psychology, 9(1), 16-32.

Morehouse, R. E. (2012). Beginning interpretative inquiry: A step-by-step approach to research and evaluation. New York: Routledge.

Olesen, V. (2013). Feminist qualitative research in the millenium's first decade. In N. K. Denzin, \& Y. S. Lincoln (Eds.), The landscape of qualitative research (4th ed). London: Sage.

Petersen, N., \& Gravett, S. (2000). The experiences of women academics at a South African university. South African Journal of Higher Education, 14(3), 169-175.

Pitonyak, M. (2010). The importance of belonging. Imagine, 5, 1-40.

Quinlan, C. (2011). Business research methods. Hampshire: Cengage.

Rabe, M., \& Rugunanan, P. (2012). Exploring gender and race amongst female sociologists exiting academia in South Africa. Gender \& Education, 24(5), 553-566.

Sá, J. (2002). Diary writing: An interpretative research method of teaching and learning. Eduacational Research and Evaluation: An International Journal on Theory and Practice, 8(2), 149-168.

Saldaña, J. (2013). The coding manual for qualitative researchers. (2nd ed.). Thousand Oaks: Sage.

Schutt, R. K. (2012). Investigating the social world: The process and practice of research. (7th ed.). Thousand Oaks: Sage.

Selematsela, D. (2011). Women in research. Vaal University of Technology, Vanderbijpark.

Selepe, M., Grobler, C., Dicks, E., \& Oldewage-Theron, W. (2012). The w(h)ine club: Women finding joy in academic work. Gender and Education, 24(1), 73-82.

Sieber, J. E., \& Tolich, M. B. (2013). Planning ethically responsible research. (2nd ed.). Thousand Oaks: Sage.

Smith, J., \& Firth, J. (2011). Qualitative data analysis: The framework approach. Nurse Researcher, 18(2), 52-62.

Smith, J. A., \& Eatough, V. (2008). Interprative phenomenological analysis. In E Lyons \& A Coyle (eds). Analysing qualitative data in psychology. Thousand Oaks: Sage.

Storey, L. (2008). Doing interpretative phenomenological analysis. In E Lyons \& A Coyle (eds). Analysing qualitative data in psychology. Thousand Oaks: Sage.

Tesch, R. (1990). Qualitative research: Analysis types and software tools. Abingdon: RoutledgeFalmer.

Tessens, L., White, K., \& Web, C. (2011). Senior Women in Higher Education Institutions: Perceived Development Needs and Support. Journal of Higher Education Policy and Management, 33(6), 653-665.

Theron, H. (2002). Women in academia: Late starters, late achievers. [Online] Available: http://www.scienceinafrica.co.za/ 2002/december/women.htm (February 13, 2014)

Van Rijnsoever, F. J., \& Hessel, L. K. (2011). Factors associated with disciplinary and interdisciplinary research collaboration. Research Policy, 40, 463-472.

Walton, G. M. \& Cohen, G. L. (2007). A question of belonging: Race, social fit, and achievement. Journal of Personality and Social Psychology, 92(1), 82-96.

Wayne, L. C. (1984). The epigenesist of relational systems: A model for understanding family development. Family Process, 23(3), 297318.

Wenger, E. (2006). Communities of practice: A brief introduction. [Online] Available http://www.ewenger.com/theory/index.htm (February $13,2014)$

Wenger, E., McDermott, R. A., \& Snyder, W. (2002). Cultivating communities of practice. Boston: Harvard Business School Press.

Wolfinger, N. H., Mason, M. A., \& Goulden, M. (2008). Problems in the Pipeline: Gender, Marriage, and Fertility in the Ivory Tower. Journal of Higher Education, 79(4), 388-405. 